\title{
O trabalho e a pesquisa em saúde: notas sobre a invisibilidade do trabalho técnico
}

\author{
Health work and research: \\ notes on the invisibility of technical work
}

Márcia de Oliveira Teixeira 1

\footnotetext{
1 Fundação Oswaldo Cruz, Escola Politécnica de Saúde Joaquim Venâncio. Av. Brasil, 4.365, Manguinhos, 21045-000, Rio de Janeiro RJ. marciat@fiocruz.br
}

Abstract In the past decades, the investigation of the different types of health work has become a central topic in the field of social research in health. In part, this increase is associated with the proposals for the reorganization of the health services, with the development of new professions and with the knowledge that there have been significant changes in the contents of health work. Many suggest that there are correlations between these changes and the acceleration in the process of incorporation of new technologies in the health services, thus bringing social health research much closer to the scientific and technological fields of investigation in the area of health. To the detriment of this convergence, few studies have explored the possible interfaces between the $d y$ namics of health work and that of technological research and development. In this sense, for the purpose of social analyses, technicians and researchers are usually not counted as health workers. Starting from a diagnosis of the invisibility of technical work in health research laboratories, we have tried to investigate the technicians' activities and the processes leading to the attribution of their various duties. Through the description of a female technician's work, we have gathered elements about the work organization in a laborato$r y$, the internal qualification processes and the relationship with researchers.

Key words Process of work in health, Work in health research laboratories, Laboratory studies
Resumo Nas últimas décadas a investigação das diferentes formas de trabalho em saúde tornou-se uma destacada temática do campo da pesquisa social (em saúde). Este adensamento, em parte, relaciona-se com as propostas de reorganização dos serviços de saúde, com o surgimento de novas profissões e com a identificação de alterações significativas no conteúdo do trabalho em saúde. Muitos apontam correlações entre essas alterações e a aceleração do processo de incorporação de tecnologias nos serviços de saúde, estabelecendo, assim, aproximações com o campo temático da ciência e da tecnologia em saúde. Em detrimento dessas aproximações, poucos estudos exploraram as possiveis interfaces entre a dinâmica do trabalho em saúde e a da pesquisa e desenvolvimento tecnológico. Nesse sentido, para efeito de análise social, os técnicos e os pesquisadores não figuram, usualmente, entre os trabalhadores da saúde. Partindo da descrição do trabalho realizado por uma técnica, discuto, neste texto, a invisibilidade do trabalho técnico em laboratórios de pesquisa em saúde. O intuito é explorar as relações entre as formas assumidas pela invisibilidade e as alterações no modo de organização do trabalho em um espaço determinado.

Palavras-chave Processo de trabalho em saúde, Trabalho em laboratórios de pesquisa em saúde, Práticas de laboratório, Estudos de laboratório 


\section{Introdução}

Nas últimas décadas a investigação das diferentes formas de trabalho em saúde tornou-se uma destacada temática do campo de pesquisa social em saúde. Este adensamento, em parte, relaciona-se com as propostas de reorganização dos serviços de saúde, com o surgimento de novas profissões e com a identificação de alterações significativas no conteúdo do trabalho em saúde. Muitos estabelecem correlações entre essas alterações e a aceleração do processo de incorporação de tecnologias nos serviços de saúde, estabelecendo, aproximações com o campo temático da ciência e da tecnologia em saúde (Mendes Gonçalves, 1994).

Em detrimento dessas aproximações, poucos estudos exploraram as possíveis interfaces entre a dinâmica do trabalho em saúde e a da pesquisa e desenvolvimento tecnológico (Teixeira, 1997, 2002, 2003). A discussão das formas de trabalho, dos processos de formação e de profissionalização de técnicos e pesquisadores, em geral, está presa às analises do processo de institucionalização da pesquisa científica e do desenvolvimento tecnológico. Nesse sentido, os técnicos e os pesquisadores não figuram, usualmente, entre os trabalhadores da saúde.

Não podemos, por conseguinte, pensar em formas de controle social e de discussão do trabalho e dos processos de formação diante do desconhecimento e da invisibilidade do trabalho e dos trabalhadores técnicos envolvidos com a pesquisa e com o desenvolvimento tecnológico em saúde (Shapin, 1991; Sims, 1999).

Partindo da descrição do trabalho realizado por uma técnica, discuto, nesse texto, a invisibilidade do trabalho técnico em laboratórios de pesquisa em saúde. O intuito é explorar as relações entre as diferentes manifestações da invisibilidade e as alterações no modo de organização do trabalho em um espaço determinado.

Procuro, desse modo, correlações entre o repertório de atividades técnicas, as práticas de produção dos conhecimentos e artefatos tecnocientíficos em saúde e a invisibilidade do trabalho técnico.

Para a consecução deste objetivo, e em função dos limites próprios de um artigo, ative-me à parte dos resultados de um projeto realizado entre 2000 e 2002, cujo propósito era discutir o processo de atribuição de um determinado elenco de atividades aos técnicos de nível médio e aos de nível superior em um laboratório de pesquisa em saúde (Teixeira, 2002). Todavia, ocu- po-me aqui apenas da técnica de nível superior. Essa opção redundou em uma amostra extremamente reduzida, porém justificada pela decisão de conter o universo de análise, não enveredando, por exemplo, na contraposição do nível médio com o nível superior. $\mathrm{O}$ trabalho de campo se baseou no uso de entrevistas semi-estruturadas com a equipe do laboratório, na história de vida da técnica (Ana), em um período de cinco meses de observação no laboratório, além do levantamento de fontes documentais (Teixeira, 2002). O laboratório, seus pesquisadores, assistentes e técnicos foram identificados pelo uso de pseudônimos. Este recurso foi acordado antes do inicio da pesquisa de campo. Muito embora este recurso comprometa qualquer tipo de abordagem historiográfica, considero-o válido para o estudo de processos locais de P\&DT cujos desdobramentos ainda estão em curso.

Este texto está organizado em duas partes. Inicio traçando um breve e incompleto painel da temática, destacando a invisibilidade dos técnicos e dos próprios laboratórios de pesquisa e de desenvolvimento tecnológico como espaços de trabalho em saúde. A segunda parte é toda ela dedicada à descrição das atividades realizadas pela técnica selecionada e por breves considerações sobre sua história no espaço de trabalho. Nessa descrição reúno elementos sobre a organização do laboratório, cujo objetivo é estabelecer correlações entre o seu repertório de atividades e os arranjos organizacionais ali existentes. Considero que a análise dessas correlações possibilita um maior entendimento da invisibilidade dos técnicos no processo de produção de conhecimentos tecnocientíficos. Ao longo de todo o texto, estabeleço diálogos com autores que lidam com esta temática em outros contextos sociais (Sims, 1999; Barley, 1996).

\section{Antecedentes}

As análises dos processos de trabalho, das formas de distribuição de atividades e suas atribuições, bem como dos processos de profissionalização na saúde, em geral, estão circunscritas aos serviços de saúde e aos profissionais de nível superior. Predominam, desta feita, estudos sobre o trabalho e o processo de profissionalização de médicos e enfermeiros. Esta concentração pode ser relacionada às posições desses profissionais no sistema de saúde durante longo período histórico. Privilegia-se, de certo modo, as relações entre médicos e enfermeiros com as práticas de 
cura. Um outro fator relevante é o reconhecimento desses profissionais como atores políticos privilegiados no processo da reforma sanitária e na estruturação do Sistema Único de Saúde (SUS).

Nos últimos anos, o panorama das análises do trabalho em saúde vem sofrendo alterações graduais. Alguns fatores têm concorrido para estas alterações, como a diversidade na composição das equipes de saúde. Apesar dessa ampliação, parte das formas de trabalho compreendidas no setor saúde ainda não foram devidamente contempladas, perseverando a concentração nos serviços de saúde. Assim, há poucas análises das formas de trabalho envolvidas com o controle de qualidade, com a produção de insumos e com a pesquisa e o desenvolvimento tecnológico.

\section{Pesquisa e desenvolvimento tecnológico: um mundo à parte}

A discussão do espaço de produção de conhecimentos tecnocientíficos esteve invariavelmente presa às políticas públicas de $\mathrm{C} \& \mathrm{~T}$, à relação do processo inovador com o desenvolvimento econômico e à difusão dos conhecimentos. Exceção para os estudos sócio-históricos das profissões e das instituições de formação científica. Entretanto, pouco se conhece das práticas locais contemporâneas de distribuição de trabalho, das relações entre a qualificação e o desempenho de atividades e entre os trabalhadores no interior dos laboratórios de pesquisa, além das práticas de aprendizagem e de disseminação de conhecimentos. Em especial, pouco se conhece do trabalho realizado pelos técnicos de nível médio e de nível superior no interior dos laboratórios de pesquisa nacionais. Este desconhecimento foi traduzido como invisibilidade do trabalho técnico por Steve Shapin (1991).

A "invisibilidade" do trabalho técnico no processo de produção dos conhecimentos científicos pode ser tratada de duas formas. De imediato, podemos relacioná-la à divisão social do trabalho, na qual o trabalho intelectual, mais identificado com os pesquisadores, é mais valorizado. No trabalho técnico, por seu turno, são salientadas as competências manuais, atitudinais e lingüísticas em lugar dos conhecimentos tecnocientíficos (Shapin, 1991; Teixeira, 2003).

Porém, a invisibilidade está nas cercanias de algumas concepções da ciência e da tecnologia circulantes nas sociedades capitalistas ociden- tais. Nelas, a consideração da ciência e da tecnologia como processos sociais de produção de formas de conhecimento e de intervenção no mundo é negada (Shapin, 1991). De fato, numerosas anedotas nos fazem pensar, mesmo hoje que nós dizemos ser a época da Big Science, nessa concepção individualista da ciência como uma revelação. Ela constitui a base cultural que explica a invisibilidade dos técnicos e de outras categorias associadas à pesquisa científica, assim como nossa tendência de ver a ciência como uma pura atividade de pensamento em lugar de uma forma de trabalho (Shapin, 1991).

Uma das possibilidades de reversão da invisibilidade é a aproximação com novas formas de lidar com as ciências e com as tecnologias. Nelas, o entendimento do processo de produção dos conhecimentos está associado às práticas realizadas no interior dos laboratórios. Nesse sentido, a reversão da invisibilidade dos técnicos está imbricada à discussão das práticas experimentais e de rotina, as quais contam com a participação intensiva de técnicos. Pensar nessas práticas é um modo de tratar das formas de trabalho e dos arranjos organizativos que enformam o processo de produção dos conhecimentos tecnocientíficos (Sims, 1999; Law, 1997).

Este texto foi influenciado por estudos centrados nas práticas de rotina e nas experimentais. Eles propuseram, ao longo de toda a década de 1980, a realização de descrições densas do cotidiano dos laboratórios. Assim, dentro do campo de Estudos Sociais da Ciência e Tecnologia (ESCT) se distingue um conjunto de trabalhos empíricos comumente designados como Estudos de Laboratório (Knorr-Cetina, 1981; Latour e Woolgar, 1993; Callon, 1989; Law, 1989). Duas características avizinham-se dessa análise. Primeiro, o uso intensivo de técnicas etnográficas para entender as conexões entre o conteúdo dos conhecimentos tecnocientíficos, as práticas cotidianas no interior dos laboratórios e a sociedade (Latour, 2000). Em segundo, a ênfase na posição dos materiais, sempre associados aos técnicos no processo de produção dos conhecimentos.

Outro destacado interlocutor é Stephen Barley (1996). Afinado com as discussões sociológicas das profissões e ocupações, partiu para a etnografia de laboratório concentrando-se especificamente no trabalho técnico. 


\section{O laboratório}

O laboratório selecionado, aqui denominado de Labter, dedica-se à pesquisa e ao desenvolvimento de vacinas a partir de duas tecnologias, a de vacinas gênicas e o uso de vetores vivos atenuados como sistema de expressão de antígenos (toda molécula capaz de provocar a produção de anticorpos mediante presença de um corpo estranho); no caso, um vetor bacteriano - o BCG.

O projeto "Desenvolvimento de sistemas de expressão para microbactérias visando à obtenção de M. bovis BCG como veículo vacinal", nomeado cotidianamente de BCG recombinante ou simplesmente BCGr, é o maior projeto e está dividido em seis subprojetos (Dengue, Tétano, Pertussis, Difteria, Hepatite B e Leishmaniose humana), enquanto o projeto "Vacinas de DNA" divide-se em três subprojetos (Escherichia coli enterotoxigênica, Dengue e Leishmaniose humana). Este conjunto contava até 2001 com a participação de 14 trabalhadores entre pesquisadores e assistentes, sendo cinco doutores (Armando, Cristina, Rita, David, Marisa), dois doutorandos (Fernanda e Márcio), dois mestres (Solange, Mônica,), três graduados (Gilda, Paulo, Ricardo), um técnico de nível médio (Helena) e um de nível superior (Ana) (Teixeira, 2001).

O Labter está ligado a uma instituição pública, localizada no município do Rio de Janeiro, cuja principal missão é a produção de vacinas e de reativos utilizados no diagnóstico laboratorial de enfermidades.

Neste texto, tratarei exclusivamente de Ana. A partir de sua história com o Labter é possível descrever as formas de organização do trabalho, os modos de qualificação e, sobretudo, distinguir os arranjos locais que instituem suas atividades, além de estabelecer diferenciações com as atividades dos pesquisadores. Embora Ana contraponha-se à parte expressiva dos técnicos por sua sólida formação acadêmica (Martins et al., 1997; Teixeira, 1996), sua história no Labter reafirma a impossibilidade de entender o trabalho técnico tão-somente a partir de uma listagem prévia, fixa e descontextualizada de atividades.

\section{Ana}

Ana é técnica em patologia clínica e entrou para a instituição através da realização de um concurso público. Na época, já contava com boa experiência em análises clínicas (14 anos), porém terminou sendo selecionada para atuar no setor de processamento final de vacinas. Não gostou do trabalho, principalmente pela falta de perspectivas profissionais e iniciou uma busca ativa por um outro setor. $\mathrm{Na}$ época do concurso, já havia iniciado o curso de biologia, fato que pesou em sua decisão de não permanecer no processamento final. Por fim, travou conhecimento com o chefe do Labter e com suas atividades na área da recombinação gênica.

Naquela altura, o laboratório não possuía nenhum técnico de nível médio ou superior envolvido com o desenvolvimento de atividades de apoio. Ana transferiu-se para o Labter concluindo em seguida sua graduação e especializando-se em uma das áreas de interesse do laboratório - a microbiologia. Ana esteve, de início, envolvida com a execução das atividades da rotina do Labter. Em 2001, começou a preparar-se para a realização da pós-graduação na área de biologia molecular.

As práticas de rotina envolvem uma grande variedade de atividades e de técnicas com diferentes níveis de complexidade, indo desde o armazenamento de substâncias químicas, passando pelo controle do consumo de substâncias, até a preparação de soluções utilizadas nos experimentos. A rotina, por conseguinte, invariavelmente refere-se à organização geral do laboratório e à preparação de tudo que será necessário à execução dos ensaios experimentais. De certo modo, podemos tomá-las como um conjunto de práticas direcionadas à produção de uma infra-estrutura essencial à realização dos projetos e à manutenção do laboratório. Os parâmetros e os protocolos adotados nas práticas de rotinas são definidos pelos pesquisadores, pois precisam estar em consonância com as estratégias (experimentais) definidas para a execução dos projetos de pesquisa. Pequenas alterações, contudo, são realizadas durante sua execução pelos técnicos; em geral, aperfeiçoamentos visando à economia de tempo e à execução simultânea de atividades.

As práticas de rotina na maior parte dos laboratórios (Teixeira et al., 1997; Martins et al., 1997) são distribuídas entre os técnicos de nível médio, os de nível superior, os graduandos e os pesquisadores em formação (mestrandos e recém mestres). A distribuição é mais intensa quanto maior a disponibilidade de trabalhadores em atuação em um determinado momento. Em muitos laboratórios, a atividade do grupo encarregado da rotina é organizada em escalas, que podem ser semanais ou mensais. Este dispositivo é muito usado nos laboratórios de pes- 
quisa em saúde, contribuindo inclusive para a qualificação dos técnicos e pesquisadores em formação (Teixeira et al., 1997; Teixeira, 1996). A escala consiste na atribuição, em um determinado período (semanal, quinzenal, mensal), da execução de uma atividade específica a um encarregado.

Todavia, nem todas as atividades de Rotina são executadas em escala. Em alguns laboratórios, podemos encontrar atividades realizadas em escala que em outros são atribuídas a especialistas, a exemplo dos meios de cultura. Invariavelmente, cabe ao chefe do laboratório delimitar o que será executado através de escalas e o que será atribuição de um especialista.

Ana encarregava-se da atualização permanente dos controles dos estoques de substância e de soluções, mas suas principais atribuições eram a preparação das soluções comuns aos projetos em desenvolvimento no laboratório e das células competentes (células "tratadas" para que a parede celular se fragilize, tornando-as permissíveis à entrada de um DNA estranho) de E. Coli, Smegmatis e BCG. Por tratar-se de uma técnica elaborada, cujos produtos (células competentes) são centrais para o andamento dos ensaios experimentais, optou-se pela especialização. Assim, durante alguns anos, apenas Ana realizou o processamento dessas células. Em contrapartida, durante um breve período, o chefe do Labter organizou escalas para a preparação das soluções comuns a todos os projetos. Essa prática foi abandonada por decisão do chefe do laboratório após a detecção de problemas recorrentes.

A ocorrência de problemas é relativamente comum e, em geral, atribuída às diferenças individuais no processamento do protocolo técnico. As soluções tendem a ser as de uso mais disseminado, por conseguinte, são consideradas essenciais à execução de um grande número de técnicas experimentais. Em estudos anteriores, observei que os laboratórios implicados com a produção de insumos e o controle de qualidade costumam optar pela instituição de um único profissional para execução destas atividades, ao contrário daqueles direcionados à pesquisa que privilegiam o rodízio de profissionais, qualificando um maior número (Teixeira, 1996; Martins et al., 1997). A especialização tende com o tempo a eliminar a possibilidade de erros advindos das diferenças pessoais na execução das técnicas, contribuindo, ainda, para a redução da perda de materiais e de tempo, bem como dos problemas com os experimentos. Entretanto, exige um conjunto de trabalhadores técnicos e/ou assistentes mais estável.

No caso do Labter, além das perdas, alguns fatores parecem ter contribuído para a escolha da especialização em detrimento da escala. O laboratório pôde dispor de Ana e depois de Helena para a realização destas atividades. Ao longo de todo o período de existência do Labter, verifica-se uma carência de assistentes de pesquisa (graduandos, mestrandos, recém mestres) para um grupo relativamente grande de pesquisadores. De fato, o Labter possui uma organização um tanto incomum, onde cada pesquisador é responsável pela coordenação de um projeto.

Em muitos laboratórios, projetos de grande envergadura, como o BCGr-Dengue, reuniriam uma única equipe composta por pesquisadores, técnicos e assistentes (Teixeira, 2001). Os efeitos mais imediatos são o grande volume de atividades sob a responsabilidade de cada pesquisador e uma gama extremamente limitada de opções de organização para a realização das atividades. Um terceiro elemento, relevante para o modo de organização, é o fato de os pesquisadores assumirem o preparo das soluções específicas aos seus respectivos projetos, ficando o técnico encarregado das de uso comum.

Muito embora tivesse uma formação técnica (patologia clínica) anterior à sua entrada no Labter, Ana precisou aprender grande parte das técnicas e, sobretudo, dos protocolos utilizados. Os protocolos podem ser definidos como descrições minuciosas das técnicas, nas quais todos os parâmetros (quantidades, diluições, acidez) estão fixados. Como tais, constituem-se em documentos oficiais do laboratório e não podem ser retirados de seu espaço físico. Para cada técnica há um grande número de protocolos possíveis, implicando sempre um período de aprendizagem prática. Esta diversidade é efeito da padronização de variantes pelos pesquisadores e técnicos motivados pela necessidade de ampliar o uso das técnicas, otimizá-las ou adequá-las às novas condições de uso. Observei ressalvas do tipo "método padronizado por Maria Helena para amplificação de proteínas” ou "protocolo geral de Labter" ou ainda "técnica realizada por Paula, diferente da do protocolo geral de Labter", no caderno de protocolos de Ana.

No período inicial de qualificação, Ana contou com Armando e Márcio e, em menor grau, com Gilda, primeiros pesquisadores do laboratório. Suas atividades sempre estiveram diretamente referidas às dos pesquisadores. 
Esta qualificação "em serviço" ocorreu através da adoção de um dispositivo largamente empregado nos laboratórios de pesquisa, inclusive para os pesquisadores em formação - observar a execução, executar conjuntamente e, em seguida, sob a supervisão (Martins et al., 1997). No entanto, o Labter dispõe de outros mecanismos de qualificação, cuja principal característica é o caráter coletivo. Refiro-me aos seminários internos do Laboratório. Assim, paralelamente à realização da graduação em biologia e da qualificação "em serviço", Ana participava ativamente destes seminários.

Os seminários, organizados pelo chefe do laboratório, giram fundamentalmente em torno da discussão de artigos e dos resultados de cada projeto. A cada início de semestre, uma listagem é preparada, de modo que a cada semana um pesquisador se ocupe da condução do seminário, intercalando a apresentação de um artigo com a exposição semestral de seus resultados. Eventualmente, realizam-se discussões de teses. Em todas as situações procura-se estimular o compartilhamento das dúvidas, das dificuldades e das soluções encontradas individualmente pelos pesquisadores do Labter ou por pares de outras instituições. É uma oportunidade para conhecer novas técnicas e protocolos, combinar a realização de um novo experimento e explorar as possibilidades para a interpretação dos resultados. Para Ana e para os pesquisadores em formação, foi um espaço no qual a experiência prática e os conhecimentos tácitos (Polanyi, 1962) eram confrontados e aliados ao conhecimento teórico. Ocorre também a aprendizagem dos modos de argumentação predominantes no campo de conhecimento do Labter (Santos, 2000).

O nome de Ana figurou, nas listagens relativas aos anos de 2000 e 2001, como encarregada dos experimentos com a proteína $\mathrm{NS}_{3}$ dentro do projeto Dengue - BCGr. No entanto, essa participação ativa dos técnicos não é corriqueira nos laboratórios de pesquisa (Teixeira, 1996). Nesse sentido, a atuação de Ana merece maiores esclarecimentos.

A delimitação mais rigorosa de Ana às práticas de rotina foi gradualmente rompida. Ana foi progressivamente envolvendo-se com a execução de atividades específicas aos subprojetos do BCGr, assumindo algumas funções que estavam sob a responsabilidade dos pesquisadores $\mathrm{e}$ assessorando-os na realização de experimentos ou na sua preparação. Em outros laboratórios, esse repertório de atividades está a cargo dos as- sistentes de pesquisa, sobretudo graduandos e mestrandos (Teixeira, 1996).

Ana passou a manter um cronograma de práticas experimentais com o BCGr-Tétano, coordenado por Márcio e David, e, quase simultaneamente, assumiu algumas atividades no projeto BCGr - Difteria, coordenado por Gilda. Mas, por algum tempo, suas atividades concentraram-se no subprojeto BCGr - Dengue, uma vez que sua monografia de conclusão de graduação abordou a proteína não-estrutural $\mathrm{NS}_{3}$, uma das possíveis candidatas à imunovacinal eleita pelo laboratório.

Essa atuação no projeto BCGr-Dengue, coordenado por Marisa, marca uma mudança significativa na inserção de Ana. Neste subprojeto e, em parte, no BCGr - Tétano, Ana abandona a execução das práticas da rotina, o auxilio na preparação dos materiais e na realização de etapas de alguns experimentos, passando à execução integral dos experimentos. O efeito mais visível é sua atuação qualificada nos seminários de discussão de resultados.

A experiência e a qualificação adquiridas nos subprojetos BCGr - Dengue e Tétano impulsionam outro deslocamento de Ana. Em 2000, o laboratório inicia uma pesquisa em colaboração com um outro laboratório em torno de uma vacina contra Leishmaniose humana utilizando o BCGr como vetor (Teixeira, 2001). No Labter, a parte experimental deveria ser executada por uma pesquisadora (Mônica) contratada com recursos do Programa de Capacitação de Recursos Humanos para Atividades Estratégicas (RHAE). Embora detivesse conhecimentos e experiência prévia com a avaliação imunológica de imunovacinais, Mônica tinha pouquíssima experiência com a utilização (de técnicas) da biologia molecular para o desenvolvimento de vacinas. Armando (chefe do laboratório) determinou que Ana realizasse os experimentos com Mônica e ficasse encarregada do repasse dos protocolos testados na primeira fase do projeto. Sua experiência com o BCG e com as células de E. Coli e Smegmatis foram fundamentais para a execução dos ajustes necessários à realização das estratégias experimentais iniciais do projeto. $\mathrm{O}$ estreitamento das relações de Ana com os dois projetos, mas em especial com o segundo, atestam o reconhecimento de sua qualificação pelos pesquisadores nas diferentes etapas da recombinação genética. E, a certa altura, seu caderno de anotações podia ser tomado como síntese das atividades do laboratório. 
Destarte, nesse ínterim, Ana desembaraçase gradualmente das atividades da rotina laboratorial, assumidas quase integralmente por Helena (Teixeira, 2003). A ampliação das atividades de Ana relaciona-se, dessa forma, com a diversidade de projetos em curso e com capacidade tecnocientífica desta profissional. Porém, a distribuição de atividades entre técnicos, assistentes e pesquisadores nem sempre está relacionada com a qualificação teórico-empírica. No Labter, a pequena disponibilidade de assistentes de pesquisa e de técnicos produziu delimitações; implicou, por exemplo, a especialização inicial de Ana (e posteriormente de Helena) e foi um dos elementos do abandono da organização de escalas.

A partir de 1999 as atividades de Ana passaram a ser descritas como atividades de desenvolvimento tecnológico nos documentos oficiais do laboratório. Ou seja, descrição similar à utilizada para as atividades realizadas pelos pesquisadores. Podemos indagar então se ao longo desse processo Ana "tornou-se" pesquisadora. Uma possibilidade é discorrer sobre as práticas experimentais do laboratório, seus modos de organização e sobre o trabalho dos pesquisadores.

\section{Trabalhos de técnicos e suas delimitações}

Ao mencionar as práticas de rotina, destaquei a diversidade de atividades, de técnicas e de protocolos, bem como a gradação da complexidade tecnocientífica, além da possibilidade de a execução ficar a cargo dos técnicos (de nível médio ou nível superior) ou dos assistentes de pesquisa. De fato, todos podem participar simultaneamente da execução das atividades da rotina, caso o laboratório adote o sistema de escala. No Labter, todavia, a rotina é distribuída entre técnicos (atividades mais gerais) e pesquisadores (atividades específicas dos projetos individuais).

Nas práticas experimentais, em contrapartida, encontramos uma forma de organização mais rígida, compartilhada por muitos laboratórios e encontrada no Labter (Martins et al., 1997; Teixeira et al., 1997). Não se utilizam escalas independentemente da disponibilidade de trabalhadores. As equipes de trabalho e as atribuições individuais são delimitadas no momento da elaboração do projeto e confirmadas ou redistribuídas a cada avaliação das estratégias experimentais. Trata-se de um modo de organização sustentado pela especialização e conjugado à valorização da máxima qualificação.
Entretanto, trata-se de uma qualificação permeável à experiência prática, não somente à certificação acadêmica (Barley \& Bechky, 1994).

Nos ensaios, os pesquisadores exploram os limites dos enunciados científicos, lançando mão de uma grande diversidade de técnicas e equipamentos. Torna-se fundamental dominar os materiais empregados, conhecer os equipamentos, as soluções e as técnicas selecionadas (Sims, 1999). É desejável, igualmente, ter algum domínio das possíveis variações de uma mesma técnica, conhecendo outros protocolos. $\mathrm{O}$ encarregado (técnico, assistente ou pesquisador) pela execução do experimento deve ser capaz de prover a equipe de informações sobre as alternativas disponíveis, detectar funcionamentos inadequados dos instrumentos e problemas de diferentes ordens durante a realização de um ensaio (Barley, 1996). Cada etapa do ensaio, cada pequeno traço dissonante ou recorrência deve ser registrada no caderno de anotações individuais para posterior relato.

Ana manifestava pleno domínio desse conjunto de conhecimentos em seu cotidiano de trabalho. Nos ensaios, ela detinha-se na produção de dados primários (fotos, tabelas, anotações), frutos de experimentos isolados e repetitivos, que eram posteriormente acumulados, registrados, confrontados pelos pesquisadores; na preparação de equipamentos, envolvendo sua testagem prévia, a detecção de problemas nos equipamentos capazes de comprometerem os resultados; na testagem de novos protocolos antes da realização do ensaio; ao estudo detalhado de cada protocolo; ao preparo de soluções específicas; à observação dos parâmetros definidos pelos pesquisadores.

Para Barley e Bechky (1994), esse conjunto de atividades constitui uma forma de intermediação (Sims, 1999). A argumentação de Barley toma a intermediação em um sentido largo. Em uma primeira dimensão, temos um conjunto de atividades cujo resultado é insumo para o trabalho; em outra, os pesquisadores. Porém, o trabalho técnico notabiliza-se em Barley (1996; e Bechky, 1994) como mediação entre o mundo material (substâncias, equipamentos, animais de laboratório) e o mundo das representações (gráficos, tabelas, imagens) resultantes da tabulação dos resultados dos ensaios. Os técnicos estabelecem uma interface empírica, enquanto operam os equipamentos e cuidam vigilantemente do seu funcionamento. $\mathrm{O}$ trabalho técnico se distingue pela articulação estreita com os equipamentos e com os dispositivos de ano- 
tação, visualização e tabulação dos resultados parciais.

Tudo isso foi identificado nas atividades de Ana junto ao projeto BCGr - Tétano, Dengue e Leishmania. Todavia, no Labter, essas características também podem ser utilizadas para descrever o trabalho dos pesquisadores. Uma questão é identificar a especificidade da prática experimental dos pesquisadores no Labter, para então delimitar o trabalho da Ana.

$\mathrm{Na}$ descrição, fiz referência ao fato de os padrões técnicos e de os protocolos serem definidos pelos pesquisadores. Eles também estão encarregados da elaboração das estratégias adotadas para a realização dos experimentos. Os pesquisadores precisam definir como abordarão as hipóteses e os problemas por eles formulados. Estas definições apóiam-se na discussão de outros projetos, na leitura de artigos e em uma análise permanente do "estado da arte" de seu campo de pesquisa. Esta análise estabelece igualmente um determinado padrão para a comprovação de suas respostas, delimitando quais testes deverão ser feitos para a legitimação de seus resultados. No limite, as estratégias atingem a decisão de onde e quando publicar.

Estas definições e ações conformam as "estratégias experimentais” (Sims, 1999). As estratégias assumem a forma de um cronograma de experimentos que serão realizados em um determinado período de tempo, envolvendo um conjunto de protocolos selecionados para cada uma das técnicas envolvidas no ensaio. Desse modo, as estratégias experimentais organizam o trabalho no laboratório em um determinado período de tempo; a partir delas, novas rotinas serão estabelecidas, enquanto outras serão mantidas. Assim, o preparo de uma solução pode ser incorporado ou retirado da rotina, enquanto um novo protocolo para a execução de uma técnica deve ser aprendido e padronizado. A rotina é, em larga medida, delineada pelas estratégias experimentais elaboradas em uma determinada conjuntura.

As ponderações e observações de técnicos que como Ana executam (integral ou parcialmente) os ensaios experimentais constituem-se em fontes de informação para os pesquisadores avaliarem tanto os resultados quanto as estratégias de pesquisa (Barley, 1996; Latour e Woolgar, 1993; Sims, 1999). Um exemplo é a participação de Ana nos seminários do Labter discutindo os resultados dos projetos Leishmania e Dengue. A análise coletiva dos resultados compreendia as interpretações de Ana sobre as si- tuações ocorridas ao longo dos ensaios e a eficácia das alterações introduzidas pelos pesquisadores para solucionarem falhas anteriores. Sua narrativa do modo como cada um dos protocolos selecionados foi operacionalizado também era muito valorizada. Estas interpretações e narrativas explicavam discrepância com os resultados anteriores ou inconsistências (às vezes positivas) com os registrados na literatura. Ao longo do jogo de perguntas e respostas, Ana fornecia elementos para os pesquisadores considerarem alterações na estratégia, buscarem outros protocolos e até pesquisarem problemas com as substâncias utilizadas.

Porém, a participação dos técnicos não costuma ir além das observações que conduzem à interpretação dos resultados. E parte expressiva da atividade dos pesquisadores está concentrada precisamente na interpretação dos resultados. A elaboração, a análise e a redefinição das estratégias experimentais CONSTITUEM o trabalho em si dos pesquisadores nos laboratórios, estejam eles ou não diretamente implicados com a execução dos experimentos (Sims, 1999).

$\mathrm{E}$ isso foi observado no Labter e com relação à participação de Ana na realização de ensaios experimentais em cada projeto. Os pesquisadores encarregados dos subprojetos $\mathrm{BCGr}$ e daqueles ligados ao projeto vacina de DNA partilham com os poucos assistentes e com Ana a execução dos ensaios. Todavia, apenas eles elaboravam as estratégias experimentais. Ana executava em todos os casos as estratégias estabelecidas no diálogo entre os coordenadores de cada projeto e o chefe do laboratório, que não participava diretamente da execução. Por mais que ela participasse do processo de avaliação dessas estratégias, não possuía autonomia para alterá-las. Qualquer decisão em torno das estratégias implicava a "ausculta" de Ana e a "decisão" dos pesquisadores e da chefia.

Assim, o exercício da intermediação, proposto por Barley e Bechky (1994), implica um tipo de transferência de conhecimento entre os técnicos e os pesquisadores; conhecimentos eminentemente práticos acerca da operacionalização das técnicas e dos equipamentos, bem como sobre as condições de realização dos experimentos. Esse conjunto de conhecimentos práticos configura um determinado modo de lidar com materiais e equipamentos nem sempre associado ao domínio teórico. A experiência adquirida ao longo dos anos de trabalho nas bancadas tornou Ana imprescindível para o Labter (Barley \& Bechky, 1994), porém não alterou 
completamente sua posição na interpretação dos resultados e no processo de elaboração das estratégias experimentais.

\section{Considerações finais}

Antes de retornar à invisibilidade e suas diferentes manifestações em cada circunstância, destaco alguns pontos do texto. A história de Ana permitiu-me identificar um repertório de atividades e de relações que situam seu trabalho em relação ao trabalho dos pesquisadores em diferentes circunstâncias.

Técnicos designam uma ampla variedade de qualificações, implicando ou não a certificação. A identificação de um rol de atividades como próprias aos técnicos, por seu turno, não comporta simplificações e generalizações. Como o Labter exemplifica, pesquisadores e seus assistentes (pesquisadores em formação) também circulam por este campo. Técnicos realizam atividades inseridas nas práticas de rotina, porém também participam da realização de uma gama diversificada de atividades nas práticas experimentais, podendo, em alguns laboratórios, assumir integralmente sua execução (Barley, 1996).

Logo, este rol pode ser estendido ou muito comprimido. Não há, considerando todas estas ponderações, formas de estabelecermos a priori um repertório de atividades como próprias aos técnicos independentemente do espaço e de suas relações em uma determinada circunstância. Não há, por conseguinte, um repertório básico, tampouco uma identidade fixa entre trabalhadores, atividades e a qualificação anterior. A composição de um repertório, bem como das fronteiras entre técnicos, assistentes e pesquisadores implicam um exercício de reterritorialização (Guattari \& Rolnik, 1986). É preciso indagar, em cada caso, quem é o técnico, o que faz, com quê e com quem faz.

Proponho tomar a reterritorialização como necessária à discussão da invisibilidade. Considero, por conseguinte, que a invisibilidade se manifesta de modo diverso em diferentes circunstâncias. Desse modo, tal qual o trabalho técnico, ela não é una, fixa e não pode ser inteiramente determinada a priori. Em parte, a invisibilidade é efeito da divisão do trabalho social e das dinâmicas do processo de produção de conhecimentos científicos. Porém, também deve ser tratada como efeito de dinâmicas locais, de micro-evento, de pequenos deslocamentos em um espaço determinado.
Quando Ana estava presa às atividades de rotina, era possível situar a invisibilidade do trabalho técnico de um modo. Tratava-se, primeiro, de delimitar a rotina, enumerando e nomeando suas atividades. Uma segunda linha envolve a discussão de como a rotina daquele laboratório se relaciona com a sua produção de conhecimento. A rotina é invisível como componente do conhecimento científico, ou seja, como produtora em si de conhecimentos. Em geral, não se recorre à sua análise para o entendimento do conhecimento científico. Esta posição acessória ou secundária da rotina transborda para os trabalhadores restritos a ela, quando o foco é o conhecimento científico produzido. Curiosamente, essa posição nem sempre transborda para os equipamentos e materiais, uma vez que reencontramos muitos nas atividades experimentais. O ostracismo da rotina só é corrompido quando o foco desloca-se para a análise do processo de produção do conhecimento científico (Latour \& Woolgar, 1993); análise que salienta as atividades cotidianas do espaço de produção desse conhecimento - o laboratório (Law, 1989).

A invisibilidade não é uma característica própria do trabalho técnico. Por um lado, ela é efeito de um determinado processo de organização do espaço de produção dos conhecimentos científicos. Nesse sentido, pode manifestarse de modo ligeiramente diferenciado. Arranjos organizacionais podem redundar na extrema delimitação do trabalho técnico à rotina laboratorial intensificando sua invisibilidade. A posição acessória da rotina como produtora de conhecimento, por conseguinte, produz uma forma de invisibilidade.

Outros arranjos podem propiciar ligeiras alterações na invisibilidade. Nos laboratório nos quais a participação dos técnicos nos seminários é ativa, bem como nos trabalhos de difusão, sua invisibilidade no processo de produção de conhecimentos é atenuada. Além disso, os arranjos que redundam em determinadas atribuições de responsabilidades e modos de distribuir atividades entre técnicos, assistentes e pesquisadores sofrem alterações a cada circunstância.

Quando Ana desloca-se para as atividades experimentais, a invisibilidade é de outra ordem. A princípio, trata-se de diferenciar seu trabalho daquele realizado pelos pesquisadores. Encontramos novamente uma divisão social do trabalho, porém ela se expressa fora das bancadas. A delimitação do trabalho técnico só é possível com a análise do processo de interpretação 
dos resultados experimentais. Ela torna explícitas as posições dos técnicos no exercício de interpretação. Todavia, a análise do Labter salientou como as interpretações dos pesquisadores comportam interpretações dos técnicos. Assim, a invisibilidade não se apresenta pela delimitação difícil entre o trabalho técnico e o realizado pelos pesquisadores durante a prática experimental. A invisibilidade se expressa como ocultamento da posição das interpretações técnicas no processo em si de produção de conhecimentos em um laboratório.

Considero que a invisibilidade do trabalho técnico de modo geral está associada a um processo de desterritorialização operado pelas ciências durante o processo de produção de conhecimento. Assim, algumas etapas da produção de conhecimento e as dimensões socioculturais são apagadas. Esse fenômeno tem sido estudado de muitos modos (Santos, 2000) e marca a

\section{Referências bibliográficas}

Barley S 1996. Technicians in the workplace: ethnographic evidence for bringing work into organization studies. Administrative Science Quarterly 41: 404-441.

Barley S \& Bechky B1994. In the backrooms of science the work of technicians in science labs. Work and Occupations 21(1):85-126.

Callon M 1989. La science et ses réseaux. La Découverte, Paris.

Guattari F \& Rolnik S 1986. Micropolíticas - cartografias do desejo. Vozes, Petrópolis.

Knorr-Cetina K 1981. The manufacture of knowledge: an essay on the contructivist and contextual nature of science. Pergamon Press, Oxford.

Latour B \& Woolgar S 1993. La vie de laboratoire: la production des faits scientifiques. Pandore, Paris.

Latour B 2000. Ciência em ação. Unesp, São Paulo.

Law J 1997. Aircraft stories: technoscience and the death of the object. Keele University, Keele.

Law J 1989. Le laboratoire et sés reseaux, pp. 117-148. In $\mathrm{M}$ Callon (org.). La science et ses réseaux. La Découverte, Paris.

Martins C et al.1997. Formação Técnica em Biotecnologia em Saúde. Relatório Final das Unidades de Produção e Serviços MS. RJ.

Mendes Gonçalves RB 1994. Tecnologia e organização social das práticas de saúde: características tecnológicas de processo de trabalho na rede estadual de centros de saúde de São Paulo. Hucitec-Abrasco, São Paulo-Rio de Janeiro.

Polanyi M 1962. Personal knowledge. Toward a pos-critical philosophy. University of Chicago Press, Chicago.

Santos BS 2000. Introdução a uma ciência pós-moderna. Graal, Rio de Janeiro.

Schraiber LB 1996. Trabalho em saúde: contribuição dos estudos sobre processo de trabalho e organização so- produção dos Estudos Sociais da Ciência nas últimas três décadas (Latour, 2000; Law, 1989). Os efeitos mais imediatos são a dificuldade de posicionarmos a rotina no interior da produção de conhecimentos, a dissociação de atividades operacionais, manuais e repetitivas dessa produção e a facilidade com que associamos as ciências à genialidade de poucos indivíduos (Shapin, 1991).

De muitos modos, a discussão do trabalho técnico implica o entendimento da organização das práticas de rotina e das experimentais em cada laboratório, de suas formas de articulação e de como aparecem nos planos de trabalho individuais. A invisibilidade, por seu turno, deve ser discutida a partir do modo como ela se apresenta em diferentes espaços, em diferentes circunstâncias e com relação à dinâmica das ciências sob a égide do mundo moderno.

cial e tecnológica das práticas em saúde. Divulgação 14: 7-9.

Shapin S 1991. Le technicien invisible. La Recherche 230: 324-334.

Sims B 1999. Concrete practices: testing in an earthquakeengineering laboratory. Social Studies of Science 29(4): 483-517

Teixeira MO 2003. Sobre o trabalho técnico em laboratórios de P\&D em saúde: apontamentos para a educação profissional. Revista Trabalho, Educação e Saúde 1(2): 289-314.

Teixeira MO 2002. Técnicos, antígenos e reagentes: discutindo as relaçães entre o trabalho e a organização de um laboratório. Relatório de Pesquisa. Convênio FiocruzFaperj.

Teixeira MO 2002. A sociologia entre biólogos e vacinas agruras do estudo de um laboratório. In História, ciência e saúde - Manguinhos. Rio de Janeiro. (No prelo).

Teixeira MO 2001. Produzindo em um laboratório - uma análise sociotécnica de suas práticas de produção de ordem. Tese de doutoramento, UFRJ/COPPE. Rio de Janeiro.

Teixeira MO et al. 1997. Análise do processo de trabalho em laboratórios de pesquisa em saúde: uma proposta de investigação. Cadernos de Saúde Pública 13(4): 711-721.

Teixeira MO 1996. Estratégias de ação individuais e competências nos laboratórios de C\&T em saúde. Processo de trabalho em laboratórios: uma análise da condição dos técnicos em unidades de pesquisa da Fiocruz. Relatório de Pesquisa. Convênio Fiocruz - Faperj.

Artigo apresentado em 15/12/2003

Aprovado em 20/3/2004

Versão final em apresentada em 20/5/2004 